\title{
Da Narrativa, Mais Uma Vez: Transcurso por As Aventuras de Pi
}

\section{Mayra Rodrigues Gomes}

Professora Titular do Departamento de Jornalismo e Editoração da ECA-USP. Professora do Programa de PósGraduação em Ciências da Comunicação da Escola de Comunicações e Artes, Universidade de São Paulo.

Email: mayragomes@usp.br
Resumo: Este artigo tem por objetivo explorar conceitos, advindos das obras de estudiosos de narrativa à luz de produções contemporâneas, porque a distância temporal de algumas nos faz esquecer da universalidade de seus achados. Procurando aplicar conceitos a produções da atualidade, o artigo adota, a título de objeto de exploração, o filme As aventuras de Pi, lançado no Brasil em dezembro de 2012. Por suas características, ele é objeto ideal para o intento já anunciado, para mostrar a pertinência de algumas notações feitas por Claude Bremond a respeito das articulações narrativas e para, ressaltando o papel do narrador, mostrar o papel da própria narrativa em nossas vidas.

Palavras-chave: narrativa; funções; alternância.

Abstract: This article aims the examination of classical concepts related to the narrative studies with the intention of demonstrate their universality or their contemporary status. In this task, it will be considered Claude Bremond notations about narrative. Furthermore, since it is motivated by the fact that the cultural production, nowadays, looks different from the ones that inspired the narrative studies in the past, the article has adopted, as exploratory object, the movie Life of $P i$ that, by its characteristics, is very appropriate to demonstrate the narrator's importance and its crossing with the narrative role in our lives.

Keywords: narrative; functions; alternation.

\section{Introdução}

Este artigo tem por objetivo explorar conceitos clássicos dos estudos de narrativa, mostrando-os em sua universalidade à luz de produções contemporâneas. Referese, como eixo conceitual, às demarcações firmadas pelas estruturas propostas por Vladimir Propp, pela análise de roteiro disposta por Christopher Vogler e pelas observações de Claude Bremond a respeito da obra do primeiro.

Além disso, como ele nasce motivado pelo fato de que a produção cultural em nossos dias, por estar distanciada temporalmente dos primeiros estudiosos da narrativa, faz pensar em produções inéditas, procuramos enfatizar eixos invariantes e o componente mítico, vale dizer, atemporal, que lhes atravessa.

Entre objetivo e motivo habita nosso desejo, atiçado pela admiração diante do filme As aventuras de Pi, objeto de nossas explorações. Mas entre os motivos, que certamente determinam objetivos, encontra-se o fato da pouca menção feita à questão da narrativa, num filme que se esmera em dirigir-se a ela o tempo inteiro, 
ou do narrador e suas escolhas, num filme em que se ressalta o papel do narrador para amarração e destino de uma história.

Muitas vezes os comentadores das narrativas contemporâneas escolhem ver componentes novos onde há, justamente, confirmação de achados antigos. Embora modulados pelos sempre renovados padrões culturais que circulam em determinado tempo e lugar, no que se incluem os aparatos tecnológicos com que se oferecem meios e modos inusitados, as narrativas contemporâneas continuam mostrando a mesma natureza outrora apontada.

Ora, com a insistência em enfatizar os novos componentes de um filme, sobretudo aqueles associados à computação gráfica e à exibição em 3D, perde-se de vista o ponto onde uma história é inovadora, não por padrões culturais emergentes ou por efeitos pirotécnicos, mas pela própria articulação narrativa que, sem fugir a uma natureza dada, nos remete de um modo especial à sua própria dinâmica e se faz, assim, renovadora. As metalinguagens podem resultar em inesperadas costuras da narração, como acontece com As aventuras de Pi.

Observaremos, a partir de Bremond, que "Toda narrativa consiste em um discurso integrando uma sucessão de acontecimentos de interesse humana na unidade de uma mesma ação" (BREMOND, 1976: 118).

Em As aventuras de Pi, título brasileiro do filme americano Life of Pi, adaptação do romance de Yann Martel, com direção de Ang Lee, que chegou até nós em dezembro de 2012, certamente temos a integração de acontecimentos que se resumem à luta por um sentido de vida e pela sobrevivência como sentido que, como veremos, sustenta a sucessão de acontecimentos.

\section{Era uma vez}

Já que anunciamos um filme como nosso objeto de exploração, iniciamos nosso caminho pelas notações do famoso estudioso e consultor de roteiros cinematográficos Christopher Vogler. Vogler nos deixou uma série de observações sobre componentes invariantes e sobre o modo de lidar com eles para a concepção de um bom filme.

Assinalou a presença de figuras da fábula e do mito, arquétipos que surgem metaforizados em outros personagens. Esse tipo de análise toma a natureza psicológica dos personagens como referência, e se casa com a de Vladimir Propp que, no entanto, toma como parâmetro a função exercida pelo personagem na narrativa.

Uma simples colocação, lado a lado, das categorias de Propp e das categorias de Vogler nos mostram a interseç̧ão mencionada, embora em posições deslocadas porque, a título de fidelidade, mantemos a sequência que cada um priorizou:

\section{Em Propp}

Vilão

Doador

Adjuvante

Pessoa/objeto procurado

O que manda

Herói

Falso herói

\section{Em Vogler}

Herói

Mentor (velha ou velho sábio)

Guardião do limiar

Arauto

Camaleão

Sombra

Pícaro 
Ainda que a terminologia evoque elementos diferenciados, na base as duas séries contemplam a mesma situação. Por exemplo, o elemento Sombra que se refere a energias do lado obscuro pode encarnar o vilão, assim como pode assumir outra face, ou função, a do Falso Herói, por exemplo, conforme a dinâmica narrativa.

Aliás, o próprio Vogler menciona explicitamente seu total entendimento dos arquétipos somente a partir do entendimento das funções de Propp, ou seja, da flexibilidade que este último conservava no interior de cada uma, embora elas fossem constantes, ou notações de invariâncias. Tal entendimento está associado ao fato de que diferentes funções, cada uma um conjunto de ações, podem ser exercidas por um mesmo personagem em blocos narrativos diferenciados, de que uma narrativa é produto de escolhas entre um elenco de funções e de que algumas funções estão correlacionadas a outras, de forma que a presença de uma implica a da outra, sem que, no cômputo geral, devam necessariamente comparecer em toda e qualquer história.

Olhando os arquétipos dessa maneira, como funções flexíveis de um personagem e não como tipos rígidos de personagem, é possível liberar a narrativa. Isso explica como um personagem numa história pode manifestar qualidades de mais de um arquétipo. Pode-se pensar nos arquétipos como máscaras, usadas temporariamente pelos personagens à medida que são necessárias para o avanço da história. Um personagem pode entrar na história fazendo o papel de um arauto, depois trocar a máscara e funcionar como um bufão ou pícaro, um mentor ou uma sombra" (VOGLER, 2006: 49).

Tomemos agora os 12 estágios da jornada do escritor que são os do herói, que Vogler construiu a partir, naturalmente de suas observações, mas, também, a partir da obra de Joseph Campbell, como ele próprio declara.

1) Mundo Comum

2) Chamado à Aventura

3) Recusa do Chamado

4) Encontro com o Mentor

5) Travessia do Primeiro Limiar

6) Testes, Aliados, Inimigos

7) Aproximação da Caverna Oculta

8) Provação

9) Recompensa (Apanhando a Espada)

10) Caminho de Volta

11) Ressurreição

12) Retorno com o Elixir

Apesar de originados em outras esferas de interesses, esses 12 estágios não deixam de ecoar as 31 funções com as quais Propp nos introduziu à análise da narrativa. Lembremos que ele ressaltava o fato de que as funções raramente vinham todas juntas e que podiam agrupar-se em pares ligados por se comporem num mesmo bloco de ação. 
Acompanharemos As aventuras de Pi considerando, como base de investigação, o esqueleto da história sob o ponto de vista de Propp, a saber, de um alinhavo de blocos de ações, ou funções. Após esse trajeto, prosseguiremos com a consideração dos estágios de Vogler.

Os acontecimentos da história são narrados por Pi adulto, em forma de flashback, muitos anos depois de suas aventuras na juventude. Trata-se de uma empreitada épica contada, como depoimento, a um jovem escritor que o entrevista à procura de um conto maravilhoso que Ihe possa inspirar em novo livro. Presume-se que, mais tarde, esse escritor será aquele a colocar no papel o relato das aventuras.

Pi Patel é um jovem indiano, cujo pai é dono de um zoológico e tem, assim como sua mãe, educação de nível superior um tanto ocidentalizada. Pi e seu irmão frequentam escola local e vivem vida tranquila em Pondicherry, na Índia. Pi é mostrado, nessa fase introdutória da trama, como um garoto que procura superar dois grandes desafios: uma aceitação, sem chacotas por parte de colegas, para seu nome bizarro e um sentido para vida.

Enfrentando o primeiro, ele demonstra persistência, perspicácia e certa inteligência, pois resolve associar seu nome ao símbolo $\pi$ da matemática. Explicando para os colegas uma função, desdobrando-a no quadro-negro da escola, repete insistentemente que seu nome é Pi, ao invés de Pipi com que é jocosamente chamado. Quanto ao segundo desafio, ele o enfrenta adotando diferentes religiões, ao mesmo tempo islamismo, cristianismo e hinduísmo. Sobre essas conversa com seu pai, pois cada uma lhe apresenta uma questão e uma resposta divergente. Ao que entendemos, Pi escolhe costurar e adotar as convergências.

Essa primeira parte do filme opera como desenho de caráter de um personagem que será narrado como herói. Tal desenho o qualifica para tanto com um conjunto de ações que se configuram com Provas de sua habilidade, para as quais há o correspondente Enfrentamento, as ações acima descritas, se seguirmos as funções arroladas por Vladmir Propp como estrutura da narrativa. Ao mesmo tempo, nessa primeira parte já há testes, inimigos e aliados.

Ocorre que, por questões financeiras, o pai de Pi precisa de abandonar o zoológico e decide, então, ir para o Canadá levando animais e família. A bordo de um navio japonês, entre preparativos e acomodações, tem início a grande jornada, que Propp definia como função de Afastamento, por terras e mares desconhecidos.

Contudo, em meio a tremenda tempestade, o navio sofre avarias que resultam em seu naufrágio. Pi, junto com uma zebra de perna quebrada, um orangotango fêmea que se desgarrou de sua família, uma hiena e um tigre de bengala, sobrevive num bote salva-vidas.

Claro que nesse bloco de ações estão enunciados tanto o Dano, o naufrágio e a perda da família, que automaticamente aponta para a Carência, a condição de náufrago num mar imenso, quanto a direção da Superação possível: a sobrevivência a ser conquistada com muito custo.

Nos primeiros momentos da vida nesse barco à deriva, a hiena ataca a zebra indefesa, arrancando-lhe pedaços de carne. Embora angustiado com a situação, Pi é Conivente, deixando espaço para que a hiena/vilão prossiga com seus assaltos à zebra, assaltos que redundam na morte do orangotango que se coloca no caminho. Pi, de tão enfurecido toma uma faca nas mãos e desafia a hiena que avança para ele, momento em que aparece o tigre de bengala, antes escondido em parte do barco coberta por lona, matando a hiena, carregando hiena e zebra para se alimentar, como fica subentendido, embora tudo isso esteja fora de nosso campo de visão, sob a meia cobertura de lona. 
A partir desse ponto, o tigre de bengala com o nome de Richard Parker (nome da pessoa que o negociou, por equivoco colocado em sua documentação) encarna o vilão, mas, não tanto...

Por 227 dias o bote vaga sem rumo pelas águas do Oceano Pacífico. Pi enfrenta, agora literalmente, a carência das condições de vida nesse bote, trava Combate ao tigre, negociando limites e fronteiras, e alcança Vitória e Reparação dessas condições, a um só tempo, com o Regresso à civilização quando o bote aporta em praia do México. Pi sai cambaleante de fraqueza, desmaia na praia e é socorrido pela população local, enquanto o tigre salta do barco e se embrenha pela floresta, desaparecendo na mata.

Do ponto de vista de Vogler, o Mundo Comum de Pi é sua vida agradável em Pondicherry. O Chamado à Aventura é certamente sua saída da Índia em direção ao Canadá, diante da qual ele demonstra relutância que pode ser vista como Recusa do Chamado, no caso, uma impossibilidade, pois há necessidade de ir e toda a família se desloca.

Contudo, na história de Pi há um outro Chamado, provocado pelo naufrágio, que o coloca diante do enfrentamento do desconhecido. Ele tem medo, hesita diante desse enfrentamento (uma forma de Recusa) para depois realmente se assumir nessa nova condição, que Vogler chamou de Mundo Especial, marca da Travessia do Primeiro Limiar, também uma marca de fim do primeiro ato.

Nesse contexto, devemos considerar o manual de sobrevivência encontrado no barco como objeto que encarna a figura do Mentor, embora possamos considerar, a partir de seus monólogos e invocações, que os deuses de suas religiões também operam como mentores.

Há Testes, Aliados e Inimigos, sobretudo com a natureza se encarnando nesses papéis. Richard Parker é inimigo enquanto aquele que pode a qualquer momento se alimentar de Pi. Mas é também o contraponto, o amigo como único companheiro, aquele que norteia as ações de Pi que sobrevive cuidando da sobrevida do tigre, aquele com quem se pode conversar, além da conversa mantida com um diário especulativo escrito a lápis em caderno encontrado entre os suprimentos, além da conversa mantida com os deuses que se mostram nas forças da natureza, assim como na execução de medidas necessárias para autopreservação: o alimento pescado, caçado ou encontrado ao acaso.

Entre a interminável tarefa de alimentar a si e ao tigre, as marés o conduzem ao mundo misterioso da ilha em que aporta e que funciona como a Caverna Oculta, pois é, como nos diz Vogler, ao mesmo tempo acolhedora e demoníaca. Marca do segundo limiar, a Aproximação à ilha se dá com cautela, implica momento sinistro, momento de Provação.

Na realidade a ilha é tão providencial que o espectador já desconfia dela desde o início e a tensão é intensificada nessa parte do enredo. Do ventre da fera, Pi colhe certa Recompensa, provisões para reencetar viagem e procurar o Caminho de Volta.

Segundo Vogler, com isso entramos no terceiro ato, momento em que o herói enfrenta, novamente, as intempéries e a fome. Quase desfalecendo, Pi e Richard Parker estão à deriva até que o barco mansamente chega a uma praia. Em sua recuperação reside a Ressurreição, e o momento apoteótico de Retorno com o Elixir se configura como a sabedoria aprendida, o conhecimento a ser compartilhado na narrativa que ele tece em seu retorno ao mundo comum. Funções da narrativa e de personagens seguidos à risca, roteiro de cinema fielmente observado, As aventuras de Pi cumpre sua promessa. 


\section{Era outra vez}

Contudo, em meio à variação de constantes, lembremos Bremond que, fazendo uma releitura dos trabalhos de Propp, ressaltou a importância dos elementos e até de um esqueleto que dê conta das articulações entre blocos de ação, ou se nos referirmos a Vogler, poderemos dizer entre estágios de uma história.

Resumindo a questão posta por Bremond, trata-se de ver que, se a narrativa é sempre um decurso do ponto de vista histórico/cronológico, há que se considerar uma lógica do antes e do depois que não se limite ao consequente, ou a relações de causa e efeito. As articulações de um ponto a outro devem, elas próprias, assim como as funções de Propp o faziam, compor um quadro característico das narrativas.

Das sequências combinadas entre si deve ser extraído um fio que as sustente e possa ser demonstrado na construção de enredos. A essa proposta Bremond responderá com a ideia de que as narrativas se articulam no movimento de passagem de um estado de Degradação ao estado de Melhoria, planos que implicam a degradação possível, o processo de degradação e a degradação produzida, assim como o melhoramento a obter, o processo de melhoramento e o melhoramento obtido.

Falando sobre rede narrativa, Bremond nos faz ver que uma narrativa opera na alternância de um estado de equilíbrio ao de desequilíbrio e de retorno ao equilíbrio, não mais o originário, mas num passo a mais ou num passo outro. Por isso:

Vê-se imediatamente que uma narrativa pode fazer alternar, segundo ciclo contínuo, fases de melhoramentos e de degradação... É menos evidente que esta alternância é não somente possível, mas necessária. Seja um início de narrativa que apresente uma deficiência (afetando um indivíduo ou uma coletividade sob forma de pobreza, doença, tolice, falta do herdeiro masculino, flagelo crônico, desejo de saber, amor etc.). Para que esta amostra de narrativa se desenvolva, é necessário que este estado evolua, que alguma coisa aconteça, própria para modificá-la. Em que sentido? Pode-se pensar, seja em um melhoramento, seja em uma degradação. De direito, entretanto, só o melhoramento é possível. Não que o mal não possa ainda piorar. Existem narrativas nas quais as infelicidades se sucedem em cascata, como se uma degradação chamasse outra. Mas, neste caso, o estado deficiente que marca o fim da primeira degradação não é o verdadeiro ponto de partida da segunda. Este degrau de parada - este sursis - equivale funcionalmente a uma fase de melhoramento, ou ao menos de preservação do que ainda se pode salvar. 0 ponto de partida da nova fase de degradação não é o estado degradado, que só pode ser melhorado, mas o estado ainda relativamente satisfatório, que só pode ser degradado (BREMOND, 1976: 119).

Uma alternância entre degradação e melhoria, em que muitas vezes se procura a preservação do estado estabelecido, compreende o movimento da sequência mais longa da história de $\mathrm{Pi}$, a saber, aquela caracterizada como segundo ato.

Pi Patel tem que procurar meios de sobrevivência para si e para Richard Parker, uma vez que, no limite, corre o risco de ser devorado por este último. Encontra instruções de sobrevivência junto aos alimentos - biscoitos, sucos e um manual - estocados no barco. Com o manual aprende a conservar água de chuva e a realizar outros tantos procedimentos básicos.

Nunca se esquece do tigre para além dessa equação de interesse pela sua própria sobrevivência, pois não descuida de lhe oferecer da água coletada. É como se sua vida dependesse da do tigre. E quando o tigre cai no mar e não consegue subir 
de volta ao barco, oportunidade única para que Pi se veja livre de sua grande ameaça, ao contrário ele constrói espécie de escada com uma prancha do barco para que o tigre possa escalá-la, salvando-o, assim, de morte certa.

Porém, no ritmo da alternância entre degradação e melhoria, a cada vez que consegue chegar a uma situação de acomodação, enfrenta revezes que o tiram de uma condição satisfatória. Tendo montado uma plataforma flutuante ao lado do bote, para manter distância do tigre, deposita nela os alimentos, para não ter que retornar com frequência ao barco. No entanto, esses alimentos acabam por desprenderem-se, afundando no mar. Tendo montado sua zona de conforto, com uma espécie de tenda que lhe dá a sombra necessária, numa tempestade tudo é destruído.

Nesses entreveros, o maior enfrentamento de $\mathrm{Pi}$ diz respeito ao fato de ter que matar para comer, uma vez que é vegetariano, e ainda apor cima, comer carne crua. Aprende a pescar para si e para Richard Parker e a se preocupar, na sequência, com a manutenção de um estoque de peixes.

Enfrenta calmarias sem perspectivas de alimentação, é resgatado da fome por uma revoada de peixes-voadores que se depositam no bote aos montões. Enfrenta baleias e tubarões, é rodeado por um mar de golfinhos que vem pontilhar a paisagem.

Sobretudo conversa com Deus, ou com os deuses que o orientam, sobre vida e morte, sobre matar ou morrer, sobre o sentido das coisas e um sentido imediato que é o da sobrevivência. Esse talvez seja, afinal, o sentido de todas as coisas sobre as quais se fala no filme.

O crítico de cinema Rubens Ewald Filho (2013 - online) escreveu em seu blog:

${ }^{1}$ Disponível em: <http://noticias. r7.com/blogs/rubens-ewaldfilho/2012/12/21/critica-de-asaventuras-de-pi/>. Acesso: jan. 2013.
Sabem o que deixa feliz... É que o cinema de hoje em dia tenha ainda espaço para uma fabula filosófica como Pi, alegórica ou não, imperfeita que seja. Mas sem dúvida um dos poucos e grandes filmes interessantes do $a_{n}{ }^{1}$.

As referências a Deus no filme, que se desdobram em questionamentos filosóficos, se dão de forma direta, como nas conversas de Pi com seu pai ou em seus monólogos enquanto vaga pelo mar. Mas, também se apresentam em forma simbólica. Esse é o caso da ilha que Pi encontra em meio a sua jornada, ilha que parece resolver todos os seus problemas pois tem vegetais de que ele se alimenta a contento, água doce para beber e banhar-se e uma multiplicação de suricatos que satisfazem o apetite do tigre.

Ora, a ilha acolhedora tem a forma de Vishnu e é regida por um ciclo disjuntivo, de dia é vida e abrigo, de noite é morte e perigo. Entre fé e razão, vida e morte, uma natureza bestial e uma espiritual, o mundo dentro do mundo, as aventuras de Pi estão enrodilhadas. E um dia, depois de estocar comida (pilhas de raízes para si, pilhas de suricatos para Richard Parker) e água, ele se lança no bote e se faz ao mar novamente.

Dizem-nos que o espetáculo de movimento, leveza e destreza de Richard Parker foi exclusivamente montado em computadores, assim como as cenas de cores intensificadas, de céus e mares estrelados na maré de plânctons que tudo ilumina.

Pouco importa uma distinção valorativa entre artefato e materialidade, entre fantasia e realidade, e menos ainda se pensarmos no final da história, ao qual chegaremos logo mais. Importa a obra de arte em que o filme se revela, com paisagens fantásticas e cenas impressionantes, tanto mais quanto potencializadas pelo 3D. 
Importa ver as sucessões de marchas e contramarchas a que se refere Bremond como um arcabouço, nada menosprezável, na costura dos estágios e dos blocos de ação.

\section{Era de vez}

$\mathrm{O}$ escritor, ou futuro escritor do livro, ouve de $\mathrm{Pi}$ adulto o relato de seu resgate. A página de jornal com matéria sobre o evento lhe é apresentada e Pi conta que, como único sobrevivente, foi interrogado por funcionários japoneses, aos quais relata a história que acabamos de resumir em meio ao apontamento de funções e estágios da narrativa.

Os japoneses não acreditam na história e insistem em saber das razões do naufrágio, que Pi desconhece, e dos fatos reais, para além das fabulações que Ihes foram contadas.

Nesse momento do filme dá-se ênfase a outro elemento que, embora estivesse no cenário desde o início do relato, era um tanto obscurecido pelas imagens maravilhosas com que se contam as aventuras. Passa para o primeiro plano em explícita menção ao seu poder de mudar a direção/sequência dos fatos, de articular uma montagem coerente, de fazer escolhas quanto a um ponto de vista, de, enfim, conferir sentido ao relato, enquanto atribui um sentido para os fatos relatados: o narrador. É sua importância que Bremond ressalta em seus comentários sobre a obra de Propp:

Diferentemente de Propp, nenhuma destas funções necessita a que a segue na sequência. Ao contrário, quando a função que abre a sequência é colocada, o narrador conserva a liberdade de fazê-la passar à ação ou de mantê-la em estado de virtualidade... Se o narrador escolhe atualizar esta conduta ou este acontecimento, conserva a liberdade de deixar o processo ir até seu termo, ou de interrompê-lo no seu caminho: a conduta pode atingir ou não seu objetivo, o acontecimento segue ou não seu curso até o termo previsto (BREMOND, 1976: 115).

E o termo previsto de As aventuras de Pi, ao contrário do que tem sido largamente comentado, não é o conjunto maravilhoso das imagens do filme e ainda menos o resgate final. O termo previsto é aquele insinuado pelo narrador que, na verdade, está à espera da pergunta de seu ouvinte para poder contar e descontar algo.

Afinal o que foi que Pi respondeu a seus inquiridores quando pressionado? $\mathrm{O}$ $\mathrm{Pi}$ Patel adulto respondeu, em flashback nas palavras do Pi convalescente no hospital, que o navio naufragou em meio a violenta tempestade. Só houve quatro sobreviventes que se abrigaram no barco salva-vidas: $\mathrm{Pi}$, sua mãe, o marinheiro japonês que estava com a perna quebrada, o cozinheiro que era, segundo ele, brutal. O cozinheiro era tão cruel que usou a carne do marinheiro até para isca. Depois de testemunhar a morte de sua mãe, provocada pelo cozinheiro, Pi o mata a facadas.

Claro que podemos ver, agora, nesses personagens que se transmutam ou intercambiam, arquétipos: o herói, o sábio, a sombra... E se nos perguntarmos, então, quem seria o tigre, Vogler nos orientara com precisão para a possibilidade insinuada.

Os arquétipos também podem ser vistos como símbolos personificados das várias qualidades humanas. Como as cartas dos arcanos maiores do tarô, representam os diferentes aspectos de uma personalidade humana completa. Toda boa história é um reflexo da história humana total, da condição humana universal de nascer neste mundo, crescer, aprender, lutar para se tornar um 
indivíduo, e morrer. As histórias podem ser lidas como metáforas da situação humana geral, com personagens que incorporam qualidades universais arquetípicas, compreensíveis para o grupo, assim como para o indivíduo (VOGLER, 2006: 50).

O futuro escritor faz o cálculo das transposições, que o espectador acompanha em suspensão, e comenta, um tanto desconcertado, que se trata de maravilhosas histórias, mas ainda não viu como isso o faria crer em Deus. Pi lhe pergunta qual das duas versões ele prefere. Seu interlocutor responde que prefere a história do tigre ao que Pi retruca: "And so it goes with God" (O mesmo acontece com Deus).

Certamente temos aí a colocação de que toda narração, na impossibilidade de conter/deter um referente, ou seja, na impossibilidade da prova de verdade ou prova de existência, porque inscreve o referente em outra dimensão, é sempre fabulação. Como tal, pertence à ordem, ou rede Imaginária, constituída a partir da dimensão Simbólica, notações aqui entendidas na acepção explicada/estabelecida pelo pensamento lacaniano.

Na narração, colocam-se em equivalência a realidade, o sonho e o mito. Caso se prefira a beleza de um arranjo que nos subtrai dos detalhes horripilantes da realidade, caso se prefira a história do tigre, por que não preferir também a da existência de Deus, que nos dá um arranjo coerente das coisas, seus sentidos e destinos nobres?

Mas algo foi introduzido em As aventuras de Pi do qual procuramos dar conta porque nos parece ser da natureza e destino da narrativa, para além de suas funções, estágios ou articulações recorrentes.

Se, junto com o escritor que ouve a história, nós, espectadores do filme, fazemos a transposição dos personagens, devemos, até mesmo por coerência, fazê-la até o fim. Se assim procedermos nos defrontaremos com situações abomináveis, porque nos remetem a um "sem fundo" ou fundamento, à ausência de sentido que nos subtrai a respostas pautadas em causa e efeito. Nós teríamos que nos haver com o Real lacaniano que permanece como substância amorfa, pré-simbólica, a nos desafiar sobre a razão, tão bem arranjada na ordem simbólica, das coisas do mundo.

Aqui a lição da psicanálise é o contrário: não se deve tomar a realidade por ficção - é preciso ter a capacidade de discernir, naquilo que percebemos como ficção, o núcleo duro do Real que só temos condições de suportar se o transformamos em ficção (ZIZEK, 2003: 34).

Pi Patel, adolescente ou adulto, enquanto narrador é quem nos dá a conhecer os fatos de duas maneiras, mas ele conta um conto tão bem, de determinada maneira, que no final das contas, ainda que sob a suspensão da dúvida, é essa maneira que vence. Vence até para nós que afinal nos recusamos a fazer o cálculo do assassinato, da antropofagia, da dívida e da culpa.

Certamente essa versão vence não só por ser maravilhosamente bem contada, mas, justamente pelo que Zizek nos aponta, porque a metalinguagem nessa narrativa é a condição sob a qual conseguimos suportar o Real, ou seja, contornando-o. Eis aí a natureza da narração, enquanto manto que recobre o mundo, tecido, como o filme bem mostra, em que nos fazemos optando por um acabamento.

Entretanto, ainda não esgotamos tudo que queríamos assinalar sobre esse final surpreendente, com sua proposta revolvente que toca o cerne das narrações. 
Gostaríamos de lembrar mais um autor que nos deixou admirável legado, dentre o qual o texto $O$ narrador, que também nos aponta essa feitura de nós na ficção.

"O narrador é a figura na qual o justo se encontra consigo mesmo" (BENJAMIN, 1994: 221). É essa a figura que Pi assume ao contar histórias que compreendem seus questionamentos que já eram ou se tornam os nossos também. Ao contar suas aventuras de um certo modo, pelas escolhas feitas Pi acerta contas com suas experiências e suas inquietações. Há algo de divino que o impele a certa interpretação, para além do bem contar, há algo na narrativa que se tece a partir de tentativas de cobrir, ou evitar, a anomia que nos espreita. No final das contas, filme e narrativa jogam o abominável, de que não há imagens, para um fora de campo.

Life of Pi ganhou quatro Oscar na 85th Academy Awards, entre eles o de sua direção pelo celebrado Ang Lee. O filme tem sido objeto de muitos comentários. Até agora, nenhum deles mencionou essa incrível façanha de fazer com que até o espectador, sabendo como provavelmente os fatos aconteceram, se recuse a aceitá-los e embarque, ele também, no acordo de justeza do narrador, acordo que tem, tudo somado, a função primeira de alijar o vazio do Real.

\section{Referências Bibliográficas}

BENJAMIN, Walter. "O Narrador: considerações sobre a obra de Nikolai Leskov". In: _. Magia e técnica, arte e política: ensaios sobre literatura e história da cultura. São Paulo: Brasiliense, 1994.

BREMOND, Claude. "A lógica dos possíveis narrativos". In: . Análise estrutural da narrativa. Petrópolis, Vozes, 1976.

CAMPBELL, Joseph. O herói de mil faces. São Paulo, Pensamento, 1995. . O poder do mito. São Paulo, Palas Athena, 2005.

EWALD Filho, Rubens. "Crítica de As aventuras de Pi". 21 dez. 2012. Disponível em: <http://noticias.r7.com/blogs/rubens-ewald-filho/2012/12/21/critica-de-asaventuras-de-pi/>. Acesso: jan. 2013.

PROPP, Vladimir (1984). Morfologia do conto maravilhoso. Rio de Janeiro: Forense Universitária.

VOGLER,Christopher. A Jornada do Escritor. Estruturas míticas para escritores. Rio de Janeiro, Nova Fronteira, 2006.

ZIZEK, Slavoj. Bem-vindo ao deserto do real!. São Paulo, Boitempo, 2003. 